\title{
A Ciência da Guerra: Epistemologia e Progresso nos Estudos Estratégicos
}

\author{
Science of War: Epistemology \\ and Progress on Strategic Studies
}

Rev. Bra. Est. Def. v. 2, nº 2, jul./dez. 2015, p. 129-150

ISSN 2358-3932

\section{ÉRICO ESTEVES DUARTE FLÁVIO PEDROSO MENDES}

Anyone for whom all this is meaningless either will admit no theoretical analysis at all, or his intelligence has never been insulted by the confused and confusing welter of ideas that one so often hears and reads on the subject of the conduct of war. These have no fixed point of view; they lead to no satisfactory conclusion; they appear sometimes banal, sometimes absurd, sometimes simply adrift in a sea of vague generalization; and all because this subject has seldom been examined in a spirit of scientific investigation (Clausewitz, 1984, p. 132).

\section{INTRODUÇÃO}

Os Estudos Estratégicos são um campo de pesquisa tardio, por isso apresenta um número significativo de inconsistências e irregularidades. A mais perversa delas é a capacidade questionável de delinear parâmetros claros e inequívocos de progresso científico. Ou seja, a falta de critérios para distinção entre pesquisa científica e compromissos expedientes, metodologias científicas e abordagens falaciosas e entre contribuições científicas e pseudociência (Kapferer, 2004, p. 64-72).

Por um lado, o íntimo relacionamento entre o estudo da estratégia com as várias agendas de governos e forças armadas, sem qualquer demarcação

Érico Esteves Duarte - Doutor em Engenharia de Produção (UFRJ) e professor de Estudos Estratégicos Internacionais (UFRGS). E-mail: ericoduarte@gmail.com.

Flávio Pedroso Mentes - Doutor em Relações Internacionais (USP) e professor de Relações Internacionais (UFU). E-mail: flaviopedroso@ie.ufu.br. 
epistemológica, tem resultado na subordinação dos Estudos Estratégicos a outras ambições normativas que comprometem a sua contribuição. Ainda que se reconheça a impossibilidade de neutralidade absoluta em um campo que lida com poder, os Estudos Estratégicos não podem ser utilizados de maneira espúria para avançar ou resolver as disputas entre grupos burocráticos e de interesse no interior dos departamentos governamentais e das forças armadas. Por outro lado, o menosprezo ou falta de zelo de acadêmicos com relação à forma como se produzem estudos estratégicos não pode ser considerada aceitável por qualquer que seja o argumento.

A utilidade social dos Estudos Estratégicos é prover conhecimento compreendido e corroborado sobre guerra e paz. Para ser capaz de qualificar as atividades estatais relacionadas, o campo deve definir claramente quais são seus objetos de estudo, teorias, fontes empíricas e critérios para validação de hipóteses (Kugler, 1993). Portanto, a qualidade da sua contribuição depende do rigor dos seus pesquisadores e da utilidade do conhecimento que produzem ao preverem e explicarem eventos relacionados ao uso da força. Nesse sentido, os Estudos Estratégicos podem e devem ser enquadrados segundo os mesmos compromissos e critérios normativos que qualquer outro campo do conhecimento considerado científico.

O presente artigo propõe a aderência à Metodologia de Programas de Pesquisa Científica de Imre Lakatos como uma solução epistemológica para o incremento na demarcação, consistência e progresso dos Estudos Estratégicos (Lakatos, 1979). Busca-se desenvolver a proposta pela exemplificação da utilidade dessa metodologia em estabelecer agendas de pesquisa sobre a guerra. Mais especificamente, o artigo usa essa metodologia como ferramenta para organização das interpretações e usos das proposições conceituais de Carl von Clausewitz em relação a abordagens alternativas.

Argumenta-se que essa proposta de demarcação epistemológica pode converter o interminável debate sobre as interpretações e usos dos conceitos de Clausewitz, principalmente devido à tragédia na comunicação de seus escritos, em um programa de pesquisa científico que clarifique como e quais conceitos de Clausewitz podem ser emendados e quais não podem; quais interpretações oferecem melhores explicações para eventos históricos e contemporâneos e quais foram falseadas; e, finalmente, quais proposições são adições ao pensamento de Clausewitz e quais pertencem a outro programa de pesquisa. De maneira similar a outros campos do conhecimento, a proposta epistemológica de Lakatos é capaz de prover rigor e orientação para um debate acadêmico mais produtivo nos Estudos Estratégicos, bem como parâmetros claros de inclusão e utilidade de novas contribuições. 
O artigo está organizado da seguinte forma: a seguir, discutimos a metodologia de Lakatos e seus critérios de aplicação; após, apresentamos nosso juízo acerca dos elementos que dão forma, à luz da métrica lakatosiana, ao Programa Clausewitziano de Pesquisa Científica; finalizando, apresentamos as considerações finais, ilustrando a utilidade analítica da abordagem pela discussão das contribuições de Julian S. Corbett e Michael Handel e sua colocação diante de tal programa.

\section{LAKATOS E A METODOLOGIA DOS PROGRAMAS DE PESQUISA CIENTÍFICA (MPPC)}

Lakatos propõe sua metodologia em meio ao principal embate da filosofia da ciência do século XX, entre o programa falseacionista de Karl Popper (Popper, 2007) e a abordagem sociológica de Thomas Kuhn (Kuhn, 1962). A profícua produção de Popper nasceu como reação à tendência verificacionista que exercia enorme influência nas primeiras décadas do século XX, talvez de forma mais plenamente representada pelos positivistas lógicos ou neopositivistas que encorpavam o Círculo de Viena. ${ }^{1}$ Em linhas gerais, para estes autores a linha de demarcação entre proposições científicas e não científicas (i.e., metafísicas) residia em sua possibilidade de comprovação a partir de um confronto direto com dados empíricos. Popper criticou o fundamento lógico dessa perspectiva, apoiada no método indutivo, afirmando que uma teoria jamais poderia ser logicamente comprovada por uma sucessão de corroborações empíricas. Tentativas de trabalhar com noções probabilísticas, último recurso verificacionista para defender a tese da comprovação factual de proposições científicas, tampouco soavam logicamente convincentes para Popper.

A solução proposta foi o programa falseacionista, a partir do qual Popper afirmava que, apesar de não poder ser logicamente comprovada por dados da realidade, uma teoria científica ainda poderia ser seguramente falseada diante de uma contraevidência empírica. $\mathrm{O}$ processo dedutivo garantiria a base lógica e a validade universal do processo. Nascia uma nova linha de demarcação entre proposições científicas e não científicas: as primeiras seriam aquelas passíveis de falseamento, ou seja, que são capazes de estabelecer a priori os seus falseadores potenciais (instâncias que, se verificadas, refutariam definitivamente a proposição); e as últimas seriam aquelas completamente protegidas contra possíveis refutações, ou seja, incapazes de estabelecer a priori os seus falseadores potenciais. Assim, "amanhã poderá ou não chover" seria uma proposição não científica, posto que não pode ser desconfirmada qualquer que seja o resultado no dia seguinte. Já “todos os cisnes são brancos" seria uma efetiva proposição científica, na 
medida em que uma única observação de um cisne negro pode, logicamente, refutar a hipótese de que todos os cisnes são brancos (Alves-Mazzotti e Gewandsznajder, 1999).

A resposta mais contundente ao programa falseacionista de Popper partiu de Kuhn e sua nova caracterização do processo da ciência. Para ele, a visão da ciência como um contínuo processo de falseamento de teorias por meio de "experimentos cruciais" e sua posterior substituição por teorias ainda não refutadas (mas refutáveis) é uma postura ingênua e ideal, que não corresponde à efetiva história do conhecimento científico. Kuhn acredita que o espírito crítico, tão importante para a epistemologia popperiana, é de fato uma exceção e representa um estágio "extraordinário" ou "revolucionário" da ciência. O estágio natural, denominado "normal" por Kuhn, seria marcado pela adesão da comunidade científica a um determinado paradigma, constituído por problemas e teorias próprios, que subsistiria mesmo diante de contraevidências que para Popper deveriam levar à sua derrocada. Elementos extracientíficos culturais, sociais, psicológicos, etc.- dariam conta dos motivos que levaram a comunidade científica a aderir a um determinado paradigma, assim como das razões que poderiam desencadear o processo de crise paradigmática e levar à sua substituição por um novo paradigma. Lakatos assim resume a divergência epistemológica dos programas de Popper e de Kuhn:

Para Popper, a mudança científica é racional ou pelo menos passível de reconstrução racional e recai no campo da lógica da descoberta. Para Kuhn a mudança científica - de um 'paradigma' para outro - é uma conversão mística que não é e nem pode ser governada por regras da razão e que recai totalmente no campo da (sócio)psicologia da descoberta. A mudança da ciência é um tipo de mudança religiosa (Lakatos, 1979, p. 112).

A Metodologia dos Programas de Pesquisa Científica se origina diretamente do embate Popper-Kuhn e pode ser encarada como uma sofisticação do programa falseacionista pela incorporação de críticas introduzidas por Kuhn e seus seguidores. A vertente do falseacionismo discutida anteriormente, que Lakatos chama de "dogmática”, encerra, para o autor, dois pressupostos principais: (i) é possível traçar uma clara linha entre proposições teóricas e proposições factuais ou empíricas; (ii) e uma proposição atestadamente factual ou empírica é verdadeira e comprovada pela realidade (Lakatos, 1979, p. 118). O corolário dos dois pressupostos somados é o critério de demarcação proposto por Popper e previamente mencionado: teorias científicas são aquelas passíveis de refutação a partir de sua confrontação com proposições factuais ou empíricas. Lakatos se aproxima de Kuhn ao criticar a plausibilidade dos pressupostos do falseacionismo dog- 
mático, reconhecendo a interdependência entre teoria e fato, e, portanto, a impossibilidade de se estabelecerem dados puramente factuais ou empíricos. ${ }^{2}$ Chega-se à conclusão de que, além de não ser capaz de comprovar logicamente uma teoria, a empiria tampouco pode refutá-la peremptoriamente. A solução kuhniana para sair do dilema colocado à forma dogmática do falseacionismo também não parece adequada a Lakatos. Apesar de reconhecer a "falibilidade dos fatos" e o fato de que os cientistas persistem tenazmente com suas teorias diante de aparentes anomalias, a epistemologia proposta por Kuhn insere um elemento de irracionalidade que Lakatos resiste em aceitar na reconstrução do processo científico. ${ }^{3}$ Popper assimila as críticas aos pressupostos de seu falseacionismo dogmático e propõe uma versão mais elaborada: o falseacionismo metodológico. Neste, a falibilidade dos fatos e a decorrente impossibilidade de falseamento decisivo de teorias a partir da empiria devem levar o cientista a tomar algumas decisões metodológicas, principalmente quanto ao estabelecimento de um "conhecimento de fundo" não problematizável, aproximando-o um pouco da metodologia dos convencionalistas franceses. ${ }^{4}$ Popper reconhece que essas decisões metodológicas envolvem riscos e um certo grau de arbitrariedade, mas as considera melhores do que a alternativa de não dispor de um método racional para apurar o conhecimento científico. Contudo, como lembra Lakatos, a nova proposta de Popper, apesar de significar um avanço, ainda nutria problemas básicos do falseacionismo dogmático e não resolvia as principais dificuldades colocadas pela história da ciência. ${ }^{5}$

O falseacionismo metodológico sofisticado é a solução que Lakatos propõe ao ceticismo epistemológico que parecia inevitável, constituindo a base de sua MPPC e derivada diretamente de sua leitura de Popper. De início, tem-se um novo critério de demarcação:

Para o falseacionista ingênuo, qualquer teoria que possa ser interpretada como experimentalmente falseável é 'aceitável' ou 'científica'. Para o falseacionista sofisticado uma teoria é 'aceitável' ou 'científica' somente se possuir um excedente empírico corroborado em relação à sua predecessora (ou rival), ou seja, somente se conduzir à descoberta de novos fatos. Essa condição pode ser analisada em duas cláusulas: que a nova teoria tenha excedente empírico ('aceitabilidade I') e que parte desse conteúdo excedente seja verificada ('aceitabilidade 2'). A primeira cláusula pode ser verificada instantaneamente por meio de uma análise lógica a priori; a segunda só pode ser verificada empiricamente e isso pode tomar um tempo indefinido (Lakatos, 1979, p. 141-42).

O critério de demarcação introduzido pelo falseacionismo metodológico sofisticado deve ser entendido a partir do reconhecimento de que teo- 
rias não são falseadas pela experiência, e cientistas, quando deparados com aparentes anomalias, esforçam-se para defender suas teorias a partir da introdução de hipóteses auxiliares para conformá-las com o comportamento anômalo. O critério racional proposto por Lakatos para a apuração do desenvolvimento científico passa a ser a natureza deste tipo de tentativa de salvar as teorias diante de evidências discrepantes. Os convencionalistas, particularmente duhemianos, já reconheciam este processo e propunham uma maneira de verificar sua "legitimidade" ou "cientificidade": a incorporação de emendas ou hipóteses auxiliares só é válida na medida em que não comprometa dramaticamente a simplicidade das teorias científicas. $\mathrm{O}$ caráter subjetivo do que simplicidade pode significar para um cientista tornava esse critério inaceitável para Lakatos. Já o critério de demarcação da forma sofisticada do falseacionismo, com suas duas cláusulas de aceitabilidade, parecia trazer de volta a objetividade desejada: a nova teoria, emendada para fazer frente a anomalias, precisa gerar excedente empírico (pelo menos parcialmente) corroborado em relação à sua predecessora. Desse critério se origina outro, que tem a ver com as regras de falseamento ou eliminação de uma teoria:

Para o falseacionista ingênuo, uma teoria é falseada por uma ('fortificada') sentença 'observável' que conflita com ela (ou que ele decida interpretar como conflitante com ela). Para o falseacionista sofisticado, uma teoria científica T é falseada se, e somente se, outra teoria T' tenha sido proposta com as seguintes características: (I) T' tem excedente empírico com relação a T: isto é, ela prevê novos fatos, isto é, fatos improváveis à luz de, ou mesmo proibidos, por T; (2) T' explica o sucesso prévio de $\mathrm{T}$, isto é, todo o conteúdo irrefutado de $\mathrm{T}$ está incluído (dentro dos limites observáveis de erro) no conteúdo de T’; e (3) parte do excedente empírico de T' é corroborada (Lakatos, 1979, p. 142).

Dos critérios acima, uma conclusão é particularmente importante: o processo científico não é e não deve ser observado em teorias isoladas, mas antes em sequências de teorias. Uma teoria só pode receber o título de científica em relação a uma anterior, sendo o árbitro final o seu excedente empírico (pelo menos parcialmente) corroborado. Similarmente, uma teoria não é falseada ou eliminada senão pelo surgimento de uma teoria melhor, com excedente empírico (pelo menos parcialmente) corroborado. Dá-se lugar a um mundo da ciência em que não há teorias isoladas, mas teorias que se sucedem e se relacionam, constituindo um programa de pesquisa científica.

Da maneira proposta por Lakatos, um programa de pesquisa tem quatro elementos principais: um núcleo duro, uma heurística negativa, uma 
heurística positiva e um cinturão protetor. O núcleo duro consiste em pressupostos invioláveis. Seu conteúdo é protegido pela heurística negativa do programa, que funciona como "um conjunto de proposições que expressam que o seu conteúdo [do núcleo duro] não pode ser diretamente desafiado ou testado" (Elman e Elman, 2003, p. 26). O delineamento do núcleo duro é uma decisão metodológica, resquício da influência convencionalista de que Lakatos julga ser impossível fugir por completo. No interior do programa de pesquisa da física newtoniana, por exemplo, o núcleo duro era formado pelas três leis da dinâmica de Newton e por sua lei da gravidade (Lakatos, 1979 , p. 133). Sua heurística negativa proibia que qualquer desenvolvimento teórico dentro do programa ferisse alguma dessas leis.

O cinturão protetor é, ao contrário, especialmente designado para ser modificado e reajustado, por meio da introdução de hipóteses auxiliares, com vistas a proteger o núcleo duro contra eventuais anomalias. É ele quem recebe diretamente os golpes da empiria e trata de acomodá-los. Seu ajustamento, no entanto, não é feito de modo desordenado, mas antes obedece às determinações da heurística positiva do programa, definida como "um conjunto parcialmente articulado de sugestões e dicas acerca de como mudar e desenvolver as 'variantes refutáveis' do programa de pesquisa; de como modificar, sofisticar o 'refutável' cinturão protetor” (Lakatos, 1979, p. 165). A heurística positiva indica que, contrariamente à concepção de um falseacionista ingênuo, o desenvolvimento de um programa de pesquisa envolve a previsão de prováveis anomalias e a elaboração de diretrizes para guiar o seu tratamento. Por isso, a heurística positiva é responsável pelo que Lakatos chama de (relativa) autonomia da ciência teórica (Lakatos, 1979, p. 163).

Uma passagem de Lakatos é particularmente útil para que se entenda como a cientificidade de emendas teóricas ao cinturão protetor deve ser verificada:

Peguemos uma série de teorias, T1, T2, T3... em que cada teoria subsequente resulte da adição de cláusulas auxiliares a (ou de reinterpretações de) uma teoria anterior com vistas a acomodar alguma anomalia, cada teoria possuindo pelo menos um conteúdo irrefutado tão grande quanto o de sua predecessora. Diga-se que tal série de teorias é teoricamente progressiva (ou 'constitui uma mudança de problema [problemshift] teoricamente progressiva') se cada nova teoria tiver algum excedente empírico em relação à sua predecessora, isto é, se ela predisser algum fato novo, previamente inesperado. Diga-se que uma série de teorias teoricamente progressiva é também empiricamente progressiva (ou 'constitui uma mudança de problema empiricamente progressiva') se parte de seu excedente empírico é também corroborada, isto é, se cada nova teoria nos conduz à real descoberta de um fato 
novo. Finalmente, chame-se uma mudança de problema de progressiva se ela é tanto teórica quanto empiricamente progressiva, e de degenerativa se ela não o for. Nós 'aceitamos' mudanças de problema como 'científicas' somente se elas forem pelo menos teoricamente progressivas; se não forem, nós as 'rejeitamos' como 'pseudocientíficas'. O progresso é mensurado pela medida de progressividade de uma mudança de problema, pela medida em que uma série de teorias nos conduz à descoberta de novos fatos. Nós consideramos 'falseada' uma teoria da série quando ela for suplantada por uma teoria com maior conteúdo corroborado (Lakatos, 1979, p. 143-144). ${ }^{6}$

Para ser considerada científica, portanto, uma teoria tem de ser teoricamente progressiva, ou seja, precisa levar à previsão de novos fatos. ${ }^{7}$ Lakatos denominou as emendas teóricas que visavam somente a salvar uma teoria de discrepâncias empíricas, sem prever fatos novos, de ad hoc 1. Para que um programa de pesquisa seja considerado progressivo, sua mudança teórica, além de ser teoricamente progressiva, deve ser empiricamente progressiva. Isso significa que pelos menos parte dos novos fatos previstos deve ser corroborada empiricamente. Lakatos denominou as emendas teóricas que, apesar de prever novos fatos, não passavam pelo teste empírico (não tinham nem parcela de seus novos fatos corroborada) de ad hoc 2. Essa rígida condição dupla de progresso corresponde aos dois critérios de aceitabilidade mencionados previamente.

Ainda um terceiro critério deve ser observado, que se pode chamar de critério heurístico. Lakatos não foi ingênuo diante da possibilidade concreta de que a agregação de hipóteses auxiliares poderia ser feita de forma desordenada e sem critérios, formando um amontoado desconexo de teorias, mesmo levando à previsão de novos fatos empiricamente corroborados. Para ele, “pode-se atingir tal ‘progresso’ por séries remendadas e arbitrárias de teorias desconexas [...] podendo-se rejeitá-las mesmo como não sendo genuinamente científicas” (Lakatos, 1979, p. 217). Neste ponto, avulta-se a importância da heurística positiva de um programa de pesquisa, que deve orientar a continuidade do seu desenvolvimento. Desta forma, além de prever fatos novos pelo menos parcialmente corroborados, uma teoria deve refletir o poder heurístico do programa de pesquisa em que se insere. Lakatos chama de ad hoc 3 as emendas teóricas que, não obstante apresentarem os requisitos de aceitabilidade propostos (não são $a d$ hoc 1 nem $a d$ hoc 2), falham em respeitar as regras colocadas pela heurística positiva do programa de pesquisa.

Finalmente, cumpre destacar os dois tipos possíveis de mudanças teóricas: intraprogramáticas e interprogramáticas (Elman e Elman, 2003, p. 28). O primeiro é caracterizado por alterações no cinturão protetor de um 
programa de pesquisa sem, contudo, ferir o seu núcleo duro. Neste caso, continua-se no interior de um mesmo programa de pesquisa, o qual é considerado progressivo se as alterações respeitarem os critérios de aceitabilidade e de heurística. Caso contrário, está-se diante de uma mudança degenerativa. O segundo tipo é originado por modificações no núcleo duro de um programa de pesquisa, contrariamente às determinações de sua heurística negativa. Aqui há a criação de um novo programa de pesquisa, formado em torno do novo núcleo duro constituído. Para que este processo seja considerado progressivo, no entanto, é necessário somente que se respeite os critérios de aceitabilidade (não sejam ad hoc 1 ou ad hoc 2), dispensando-se o critério heurístico (pode ser ad hoc 3). Essa exigência é perfeitamente natural, na medida em que a transição de um programa de pesquisa para outro não deve impor as regras da heurística positiva do primeiro. O novo programa de pesquisa constituído deve, então, desenvolver sua própria heurística positiva.

Com sua metodologia, Lakatos acreditava ter logrado apresentar uma visão racional do processo científico, apesar das inerentes limitações ao conhecimento impostas pela interdependência entre teoria e fato, e que ao mesmo tempo permitia descrever a efetiva história interna das ciências de maneira mais fidedigna do que suas principais rivais epistemológicas: ${ }^{8} \mathrm{o}$ verificacionismo, o falseacionismo ingênuo e a abordagem sociológica de Kuhn (Lakatos, 1998).

\section{O PROGRAMA CLAUSEWITZIANO DE PESQUISA CIENTÍFICA}

Nesta seção, exemplifica-se o uso da epistemologia lakatosiana como recurso para organização da pesquisa e debate acadêmicos em torno da obra de Carl von Clausewitz. Para além de se evitar o seu uso de maneira dogmática e morta - como ele mesmo condena -, a epistemologia lakatosiana auxilia no ordenamento das pesquisas que se apoiam e mesmo daquelas que se opõem e buscam superar suas contribuições. Portanto, a tentativa aqui não é de concluir um entendimento sobre a Teoria da Guerra, distante disso, mas introduzir 'regras do jogo' que permitam que os vários pesquisadores da estratégia consigam posicionar de maneira mais clara e bem embasada seus objetos de pesquisa e os graus de concordância e discordância com relação aos seus pares.

De acordo com Lakatos, a proposta de um programa de pesquisa, bem como a adesão a ele, são decisões tomadas por pesquisadores de forma voluntária e consistente. Portanto, o que se propõe a seguir não deve ser tomado como algo definitivo, mas antes como um convite a uma nova perspectiva diante do desenvolvimento da Teoria da Guerra de Clausewitz. A 
única regra de ouro é a honestidade intelectual dos interlocutores e de suas críticas. Uma regra de prata, não menos necessária ao desenvolvimento do programa, é mais difícil de ser executada: o teste empírico de proposições, o que exige compromissos e fontes de pesquisa mais rigorosos.

Uma segunda precaução - na realidade um pressuposto - é a de que as contribuições teóricas de Clausewitz vão além do Da Guerra e não podem ser restringidas a ele. As distinções, insuficiências e erros das diversas traduções e edições da obra magna de Clausewitz são bem conhecidos, como também o é a necessidade de complementar o Da Guerra com o restante dos textos do autor em suas Obras Completas (Hinterlassene Werke). Mais ainda, a proposição de um Programa Clausewitziano de Pesquisa Científica deve lidar com o fato de que o pensamento de Clausewitz apresenta diferentes estágios de maturidade, que não são claramente classificados ou mesmo reconhecidos. ${ }^{9}$ Colocar ordem em tudo isso é a promessa por trás da metodologia de Lakatos.

\section{Núcleo Duro e Heurística Negativa}

O núcleo duro de um programa de pesquisa científica é o que lhe confere identidade como abordagem distintiva em um campo de investigação empírica. Ele é protegido pela heurística negativa e qualquer violação de seu conteúdo implica transição automática a uma abordagem rival. Com relação à proposta do Programa Clausewitziano de Pesquisa Científica, ajuizamos o seguinte conteúdo:

\#1 - A centralidade do combate na guerra. Nas palavras de Clausewitz, a definição de guerra como "um ato de força para obrigar nosso inimigo a fazer a nossa vontade" (Clausewitz, 1984, p. 75) deve ser seguida pela conclusão lógica de que na guerra tudo deriva, direta ou indiretamente, do combate. Isto se dá mesmo quando o combate não tem lugar concretamente - quer dizer, quando cálculos e decisões são feitos com base não nos resultados reais do combate, mas na sua antecipação (Clausewitz, 1984, p. 95).

\#2 - A guerra como instrumento político. Na teoria clausewitziana da guerra, a relação essencial entre guerra e política não é simplesmente dada por definição - "a guerra é a continuação da política com outros meios" (Clausewitz, 1984, p. 87). Trata-se de uma conclusão lógica e empírica a partir da profunda investigação de Clausewitz sobre o fenômeno da guerra. É um ponto de chegada, não de partida, que a guerra é um verdadeiro instrumento político e não apenas a continuação da política - ou seja, que a política não só dá à luz a guerra, mas a controla e dirige plenamente.

\#3 - A superioridade intrínseca da defesa sobre o ataque. Este é o fator singularmente mais importante para explicar as diferenças entre as guer- 
ras reais e a guerra no papel (guerra absoluta). É, portanto, também o fator singularmente mais importante que dá conta do retorno do objetivo político após o início da guerra, tornando-a um verdadeiro instrumento político. ${ }^{1}$ É claro, o entendimento adequado deste poderoso elemento da construção teórica clausewitziana exige o conceito pleno de defesa - que aborda a condução da guerra como um todo e permite a consideração das manifestações estratégicas da superioridade intrínseca da defesa e os pontos culminantes do ataque e da vitória - e não simplesmente o seu conceito estrito (tático). ${ }^{1} \# 4-A$ Trindade. A Wunderliche Dreifaltischkeit ${ }^{12}$ é o que garante a correspondência, na teoria da guerra, entre os axiomas que definem a guerra e os demais conceitos e categorias analíticas para o estudo da guerra. A trindade é o que permeia a apreensão cognitiva dos elementos fundamentais da guerra: as paixões, o campo da probabilidade e do acaso, e a razão. $\mathrm{O}$ efeito dos seus relacionamentos permite a consideração dos aspectos mais amplos entre a gramática do uso da força e seus possíveis propósitos políticos. A trindade também educa o analista/ comandante sobre as considerações que devem ser vislumbradas em uma dada guerra para aprimorar o seu julgamento: as motivações das coletividades envolvidas; as condições do comandante e suas forças combatentes; e as instituições políticas que orientam ambos os lados e estabelecem seus objetivos finais.

\section{Heurística Positiva}

Propõe-se aqui que o Programa Clausewitziano de Pesquisa Científica deve abarcar todo o amplo espectro de fenômenos sociais em que a força é empregada, em ato ou potência, para fins políticos. Em outros termos, o Programa Clausewitziano pode ser legitimamente expandido para tratar de qualquer 'fato novo' que possa ser analiticamente decomposto em considerações táticas, estratégicas e políticas.

Aplicando-se a epistemologia lakatosiana, pode-se delimitar que as fronteiras heurísticas do Programa Clausewitziano são a História Estratégica do Mundo (Gray, 2007). Também é nosso entendimento que idealmente deveria ser elaborado, não fossem as restrições de espaço - que o Programa Clausewitziano não possui rival à altura no campo dos Estudos Estratégicos e de Defesa. Destarte, é honesto e útil reconhecer que o Programa Clausewitziano é, ao menos presentemente, o único edifício teórico capaz de sustentar a demanda dos Estudos Estratégicos por reconhecimento como campo de investigação científica, e as fronteiras heurísticas do programa devem ser amplamente reconhecidas como sendo as fronteiras do campo ele mesmo. 


\section{Cinturão Protetor}

O cinturão protetor organiza o conteúdo teórico de um programa de pesquisa científica. Ele compreende as proposições conceituais, hipóteses e teorias auxiliares que se tornam complementares entre si enquanto compartilham o mesmo núcleo duro. Esse conteúdo teórico deve ter como meta prever e explicar fatos da realidade relacionados aos problemas e fenômenos demarcados pelo núcleo duro e se tornar a heurística positiva do programa, ou seja, aquela sujeita a expansões e alterações. Devido a constantes emendas, o cinturão protetor nunca deve ser definitivo, mas evoluir enquanto o programa de pesquisa científica for progressivo.

Seguindo essas orientações, o que desenvolvemos a seguir são linhas gerais de pesquisa apontadas por Clausewitz no capítulo 2 do Livro 1 do Da Guerra, seu último escrito, em articulação com seu Livro 2, notadamente aquele em que ele desenvolve os elementos epistemológicos e metodológicos das suas proposições.

Teorias dos Fins: a linha de pesquisa obrigatória derivada de uma abordagem a partir de Clausewitz é com relação às metas para o uso da força através das quais objetivos políticos podem ser atendidos. Enquanto "nós verificamos que o objeto de qualquer guerra pode variar, assim como seu propósito político e suas reais circunstâncias", o emprego da força varia da combinação de três metas gerais: as forças combatentes, a sociedade e a administração pública de um oponente (Clausewitz, 1984, p. 90).

As circunstâncias políticas variam em termos de época e região, mas principalmente de uma instância de relacionamento político para outra. Clausewitz conceitua dois tipos de guerras - ilimitadas e limitadas - que abarcam todas as guerras na realidade em termos de seus parâmetros coercitivos. Portanto, uma linha constante de pesquisa é como os planos de guerra de cada sociedade podem servir a seus propósitos políticos ao longo do tempo em relação a cada um de seus rivais.

Teorias dos meios: A centralidade da guerra é o uso da força e esta é sua própria gramática. Portanto, uma agenda de pesquisa permanente é sobre as forças combatentes, em suas várias formas, ao longo da história e no tempo contemporâneo. Clausewitz aponta como as diferentes composições de forças combatentes - móveis, imóveis, permanentes, temporárias, profissionais ou amadoras - possibilitam diferentes tipos e graus de enfrentamentos e campanhas no ataque e na defesa. Ainda que todas elas sejam ungidas pelos mesmos propósitos em terra, as teorias dos meios podem ser expandidas para outros ambientes, modais e técnicas e tecnologias de combate relacionadas onde os seres humanos travam guerras entre si. 
Teorias dos métodos: no capítulo 2 do Livro 1, Clausewitz sintetiza dois tipos de estratégias - estratégias de prostração (Niederwerfungstrategie) e estratégias de exaustão (Ermattungstrategie) - e elas se desdobram em vários métodos da guerra, dependendo das condições relativas de força e da intenção positiva ou negativa de um lado sobre o outro.

Eles variam entre a destruição das forças oponentes, a conquista de seu território, a ocupação temporária ou invasão, as operações com um propósito político imediato e, finalmente, a espera passiva pelo fim do ataque do oponente. Qualquer um desses pode ser usado para sobrepor a vontade do oponente: a escolha vai depender das circunstâncias (Clausewitz, 1984 , p. 94).

Por isso, assim como as várias distinções e condições que se aplicam aos meios da guerra, os métodos da guerra também merecem ser objeto de inferência e avaliação crítica. Esses métodos são especializados e subordinados às dimensões em que se conduz guerra - terra, mar, ar e espaço. Porém, considerando a natureza da guerra, elas precisam ser de alguma maneira conectadas com a realidade social do homem em terra.

Análise crítica: Clausewitz textualmente pontua que a ambição de sua contribuição era a educação de comandantes e a elaboração de um arcabouço para se pensar apropriadamente sobre a guerra. Ele propõe a análise crítica como a metodologia para educação de pessoas sobre como pensar e tomar decisões sobre a guerra, para testar a teoria da guerra e seus conceitos e, por último, para expandir a compreensão sobre as guerras do passado e do presente.

Uma análise crítica é a investigação das principais relações causais entre decisões políticas e estratégicas, a disponibilidade de meios de combate, as interações entre oponentes e os resultados de um estudo de caso. Apesar dele não desconsiderar o recorte de guerras como um todo, o estudo é metodologicamente mais viável se limitado a uma campanha: o emprego de forças combatentes em enfrentamentos para um resultado estratégico. Contextualiza-se um caso pelas formas como decisões sobre guerra são tomadas e como uma dada sociedade apoia tais instituições políticas, as características biográficas e possivelmente psicológicas das personalidades que comandam as forças combatentes e os números e as condições destas últimas. Daí, ela se desdobra em três partes. Primeiro, a análise dos fins em que se define o tipo de guerra que se estuda - limitado ou ilimitado - e sua necessidade/utilidade para os beligerantes. Segundo, a análise dos meios em que se reconstrói uma campanha contrastanto hipóteses de conduta da campanha desenvolvidas a partir da teoria com os planos dos comandantes e, a partir disso, reconstruindo e analisando os principais enfrentamen- 
tos. Por fim, há a avaliação das decisões políticas e estratégicas tomadas, apresentando-se alternativas viáveis segundo as informações e condições que cada comandante tinha à mão em seu dado tempo, e critica-se negativamente uma dada figura histórica apenas quando uma dessas alternativas com potencial de maior sucesso ou menor dano não foi seguida.

Através de vários estudos de campanhas, Clausewitz verificou não apenas conceitos e entendimentos, mas a própria análise crítica como uma ferramenta metodológica. Por isso, o incremento de métodos para o ensino e pesquisa sobre a guerra é uma agenda de pesquisa permanente (Clausewitz, 1984, p. 141).

\section{CONSIDERAÇÕES FINAIS}

Exemplificaremos a seguir como o Programa Clausewitziano é capaz de promover um corpo unificado de estudos sobre estratégia. De um lado, defende-se que o trabalho teórico de Julian S. Corbett representa uma emenda intraprogramática ao pensamento de Clausewitz, acrescentando uma agenda de pesquisa teórica e empírica progressiva, ao mesmo tempo em que preserva o núcleo duro do Programa Clausewitziano. De outro, argumenta-se que a modificação da Trindade proposta por Michael Handel ultrapassa os limites da heurística negativa do programa e deve ser apreendida como uma mudança teórica interprogramática.

As proposições conceituais, e seus devidos testes empíricos, de Julian Corbett são, possivelmente, os principais progressos já realizados no Programa Clausewitziano. Sua pesquisa científica não apenas foi importante por organizar o arcabouço teórico de Clausewitz e reafirmar seu compromisso epistemológico para o século XX, como também é uma das mais originais contribuições sobre a guerra (Gat, 2002; Handel, 2000, p. 121; Widen, 2012).

Corbett foi quem organizou mais claramente o pensamento de Clausewitz em teorias dos fins, meios e métodos, através do qual ele reconheceu e definiu as distinções dos meios de uso da força no mar e na terra. A teoria das operações marítimas foi apresentada em Some Principles of Maritime Strategy (1911) e teve suas proposições testadas e expandidas em The Maritime Operations of Russo-Japanese War 1904-1905 (2015, publicado originalmente em 1914). ${ }^{1}$ No primeiro livro, Corbett expandiu o Programa Clausewitziano em concorrência à abordagem da guerra no mar predominante até então, baseada nas obras de Alfred Mahan (Golrdrick e Hattendorf, 1993). ${ }^{1}$ Já na segunda obra, além da verificação do poder explanatório de suas proposições, Corbett faz mais um avanço conceitual que reafirma o compromisso epistemológico e agenda de pesquisas científicas 
a partir de Clausewitz (Angstrom e Widen, 2014, p. 96). Corbett antecipou como a combinação dos meios de guerra no mar com as forças combatentes em terra resultavam em novos métodos da guerra. Ao visualizar a realidade das operações conjuntas de japoneses e russos, Corbett reafirmou a importância da educação teórica para o desenho dos planos de guerra e sinergia entre comandantes de diferentes forças e destes com a liderança política. Ele apontou como teorias da guerra são fundamentais na produção de uma solidariedade similar entre comandantes e a liderança política que compõem um conselho de guerra. Nesse sentido, a teoria funciona como uma linguagem que possibilita a devida concepção e exposição de ideias entre expoentes de distintas tradições e trajetórias políticas e militares. Mas ela é ainda um método pelo qual um conselho de guerra pode distinguir entre fatores essenciais e não essenciais e ser capaz de dar forma com precisão e rapidez a um curso de ação ou plano de guerra. A especialização e expansão dos serviços militares em estruturas burocráticas e o número e diversidade de missões impõem que as deliberações de conselhos de guerra ocorram a grandes distâncias geográficas das atuais operações e forças combatentes e com grande dificuldade de sincronização temporal. Corbett lidava com o desafio da articulação dos meios de força, globalmente dispersos, do Império Britânico. Porém, não é difícil sustentar que esse seja um problema comum entre as demais potências dos séculos XX e XXI.

Como resultado, Corbett expandiu consideravelmente a utilidade do Programa Clausewitziano. Ele emendou novos conceitos corroborados empiricamente ao cinturão protetor e reafirmou a perspectiva e compromissos normativos do núcleo duro. Com isso, ele ofereceu elementos que permitem atestar tal programa como científico e progressivo.

De outro lado, nos anos 1980, o professor do US Naval War College, Michael Handel, propôs que Clausewitz seguia sendo o grande pensador da guerra, mas apenas como um ponto de partida e demandava a revisão de sua teoria para perpetuação de sua utilidade contemporânea (Handel, 1986). Ele afirmava que a partir da Revolução Industrial uma série de alterações tecnológicas teriam modificado as realidades econômicas, sociais, políticas e, como não poderia deixar de ser, da própria guerra. Isso embasava sua proposta de revisão da Teoria da Guerra para a "era da tecnologia”. Num esforço de sistematização de todas as perspectivas tecnológicas de seu tempo, Handel tentou formular uma perspectiva tecnológica integrada da Teoria da Guerra com a Revolução dos Assuntos Militares (em inglês Revolution of Military Affairs - RMA) e da Teoria do Balanço Ataque-Defesa. Por fim, ele defendeu a revisão da trindade clausewitziana, que passaria a ter uma quarta componente tecnológica, desencadeando assim uma agenda particular de pesquisas. 
A proposta foi incorporada a uma gama de autores contemporâneos de estudos de defesa. Por um lado, por aqueles que desejaram estender o estudo dos impactos da tecnologia na guerra e na Teoria da Guerra de Clausewitz, os autodenominados Neoclausewitzianos. ${ }^{1}$ Por outro lado, pelos autores que passaram a apontar a obsolescência da Teoria da Guerra de Clausewitz (exemplarmente, Creveld, 1991 e Kaldor, 1999). É útil entender as consequências das duas agendas de pesquisas utilizando-se a epistemologia de Lakatos.

No primeiro caso, a proposta que Handel e seus aderentes empreendem é uma emenda fundamental no núcleo duro do Programa Clausewitziano. E esse grupo de pesquisadores e suas pesquisas podem apenas ser considerados como parte de um programa de pesquisa alternativo e distinto das proposições de Clausewitz e Corbett. Para serem considerados científicos, eles precisam mais do que identificar 'novos fatos': suas abordagens devem explicar os eventos previstos e explicáveis por Clausewitz e Corbett. Esse novo programa tornar-se-ia a partir de então concorrente ao Programa Clausewitziano. Para serem considerados progressivos, eles precisam ter suas proposições conceituais testadas empiricamente. Ou seja, para uma abordagem alternativa ser considerada um programa de pesquisa científica, não basta apenas explicar as anomalias do programa concorrente, pois o ganho de conhecimento seria marginal em relação a tudo que foi produzido anteriormente. É necessário prever 'novos fatos', que precisam ser (pelo menos parcialmente) empiricamente corroborados, e ser capaz de continuar a explicar os 'antigos fatos'.

No segundo caso, a busca pelo falseamento do Programa Clausewitziano é notadamente uma agenda de pesquisa degenerativa, pois segue uma heurística negativa e não contribui com a produção de conhecimento novo. A busca pelo falseamento de programas concorrentes não favorece a identificação e a compreensão de novos eventos da guerra - é, portanto, inútil. De um ponto de vista acadêmico e estrito, essa é uma orientação irracional e apenas pode ser calcada em motivações psicossociológicas, nas linhas desenvolvidas por Thomas Kuhn. Do ponto de vista da contribuição social do conhecimento, esforços dessa natureza são desperdício de recursos.

Essa argumentação sustenta que as teorias da guerra e das operações marítimas de Clausewitz e Corbett, combinadas, atendem a todos os requerimentos normativos de Imre Lakatos e sua Metodologia dos Programas de Pesquisa Cientifica e configuram um programa científico e progressivo de pesquisa. Isso também permite, ao assumir tal programa como referência, qualificar os ganhos e perdas na adesão pelos pesquisadores a agendas de pesquisas em estratégia e assim poderem melhor organizar suas contribuições em termos de foco, consistência e utilidade. 


\section{REFERÊNCIAS}

ALVES-MAZZOTTI, A. J.; GEWANDSZNADJER, F. O método nas Ciências Naturais e Sociais. São Paulo: Pioneira e Thomson Learning, 1999.

ANGSTROM, J.; WIDEN, J. J. Contemporary military theory: the dynamics of war. London: Routledge, 2014.

BALL, T. From paradigms to research programs: toward a post-kuhnian political science. American Journal of Political Science, v. 20, n. 1, p. 151-177, 1976.

BLAUG, M. Kuhn versus Lakatos, or paradigms versus research programmes in the history of economics. Hope, v. 7, n. 4, p. 399-433, 1975.

BUNKER, R. J. Technology in a Neo-Clausewitzian Setting. The Hague: Kluwer Law International, 1997.

CLAUSEWITZ, C. v. On War. Princeton: Princeton University Press, 1984.

CORBETT, J. S. Some principles of maritime strategy. London, New York: Longmans, Green and Co, 1911.

CORBETT, J. S. Maritime operations in the russo-japanese war: 1904-1905. Annapolis: Naval Institute Press, 2015.

CREVELD, M. V. The transformation of war: the most radical reinterpretation of armed conflict since Clausewitz. New York: Free Press, 1991.

DINIZ, E. Clausewitz, o balanço ataque-defesa e a Teoria das Relações Internacionais. Rio de Janeiro: Coppe/UFRJ, 2002.

DINIZ, E.; PROENÇA JR., D. A criterion for settling inconsistencies in Clausewitz's On War. Journal of Strategic Studies, v. 37, n. 6-7, p. 879-902, 2014.

DUHEM, P. Algumas reflexões sobre as teorias fisicicas. São Paulo: Ciência e Filosofia, 1989.

ELMAN, C.; ELMAN, M. F. Lakatos and neorealism: a reply to Vasquez. American Political Science Review, v. 91, n. 4, p. 923-926, 1997.

ELMAN, C.; ELMAN, M. F. How not to be Lakatos intolerant: appraising progress in IR research. International Studies Quarterly, v. 46, p. 231-262, 2002.

ELMAN, C.; ELMAN, M. F. Lessons from Lakatos. In: ELMAN, C.; ELMAN, M. F. (Ed.) Progress in international relations theory: appraising the field. Cambridge: MIT Press, 2003, p. 21-70. 
GAT, A. A history of military thought. New York: Oxford University Press, 2001.

GOLDRICK, J.; HATTENDORF, J. (Ed.). Mahan is not enough: the proceedings of a conference on the works of Sir Julian Corbett and Admiral Sir Herbert Richmond. Annapolis: Naval War College Press, 1993.

GRAY, C. War, peace and international relations: an introduction to strategic history. London: Routledge, 2007.

HANDEL, M. Clausewitz in the age of technology. In: HANDEL, M. Clauserwitz and modern strategy. London: Frank Cass, 1986, p. 51-92.

HANDEL, M. Corbett, Clausewitz, and Sun Tzu. Naval War College Review, v. 53, n. 4, p. 106-124, 2000.

HOOKER JR., R. Beyond Vom Kriege: the character and conduct of modern war. Parameters, v. 35, n. 2, p.4-17, 2005.

KAPFERER, B. Old permutations, new formations? War, State, and global transgression. Social Analysis, v. 48, n. 1, p. 64-72, 2004.

KUGLER, J. Political conflict, war, and peace. In: FINIFTER, A. (Ed.). Political science: the state of the discipline II. Washington: American Political Science Association, 1993, p. 483-509.

KUHN, T. The structure of scientific revolutions. Chicago, London: The University of Chicago Press, 1962.

KUHN, T. A estrutura das revoluções científicas. São Paulo: Editora Perspectiva, 2005.

KURTH, J. Clausewitz and the two contemporary military revolutions: RAM and RAM. In: LEE, B.; WALDING, K. (Ed.). Strategic logic and political rationality: essays in honour of Michael Handel. London: Frank Cass, 2005, p. 274-297.

LAKATOS, I. O falseamento e a metodologia dos programas de pesquisa científica. In: LAKATOS, I.; MUSGRAVE, A. (Org.) A crítica e o desenvolvimento do conhecimento. São Paulo: Cultrix, 1979, p. 109-233.

LAKATOS, I. História da Ciência e suas reconstruções racionais. Lisboa: Edições 70, 1998.

LYNN, J. War of annihilation, war of attrition, and war of legitimacy: a neo-clausewitzian approach to twentieth-century conflicts. Marine Corps Gazette, v. 80, n. 10, p. 64-84, 1996. 
MENDES, F. P. Lakatos, o realismo ofensivo e o programa de pesquisa científico do realismo estrutural. São Paulo: IRI/USP, 2013. NEURATH, O. et al. A concepção científica do mundo: o círculo de Viena. Cadernos de História e Filosofia da Ciência, 10, p. 65-76, 1986.

PETERS, R. The New Strategic Trinity. Parameters, v. 28, n. 4, p. 73-80, 1998.

POINCARÉ, H. A Ciência e a Hipótese. Brasília: Ed. Universidade de Brasília, 1984.

POPPER, K. The logic of scientific discovery. Cambridge: International Society for Science and Religion, 2007.

ZAHAR, E. Why did Einstein's Programme Supersede Lorentz's?. British Journal for the Philosophy of Science, 24, p. 95-123, 1973. 


\section{NOTAS}

1. Para a proposta central do Círculo de Viena, ver Neurath e al. (1986).

2. O exemplo extremo é a própria 'observação' direta de fenômenos, que, no limite, pode ser relacionada a uma teoria fisiológica do aparato humano de visão.

3. A crítica de que insere um elemento de irracionalidade é algo que Kuhn rejeitou veementemente. Ver, por exemplo, o posfácio de seu Estrutura das Revoluções Científicas (Kuhn, 2005).

4. Ver, principalmente, Poincaré (1984) e Duhem (1989).

5. Especificamente, Lakatos argumenta que os testes teóricos não têm tradicionalmente estado entre uma teoria e os dados empíricos, mas antes estão, pelo menos, em "embates trilaterais entre teorias rivais e o experimento"; ainda, afirma que "alguns dos experimentos mais interessantes resultam, prima facie, em confirmação e não em refutação” (Lakatos, 1979, p. 140).

6. Note-se que com a expressão "mudança de problema" (problemshift) Lakatos queria de fato dizer "mudança teórica" (theoryshift), porém preferiu não usar a última expressão por considerá-la problemática.

7. Desde a publicação da MPPC tem havido uma enorme controvérsia em torno do significado de "fato novo". Há pelo menos quatro interpretações principais (Elman e Elman, 2002, p. 238-241). Destas, a que propõe o critério de novidade heurística - também conhecido como Zahar/ Lakatos3 -, de acordo com o qual o fato anômalo que originou a mudança teórica não pode contar como instância corroborativa da nova teoria, é a mais coerente com o espírito da epistemologia de Lakatos.

8. Para a defesa particular da superioridade analítica da metodologia lakatosiana para a compreensão da evolução científica de diversas áreas do conhecimento, ver: na física, Zahar (1973); na economia, Blaug (1975); na ciência política, Ball (1976); nas relações internacionais, Elman e Elman (1997; 2002; 2003) e Mendes (2013).

9. Uma proposta importante e bem-vinda para superar estas dificuldades é o recente artigo de Diniz e Proença Jr. (2014).

10. Se não fosse pela superioridade intrínseca da defesa, a guerra absoluta resultante seria dominada por considerações táticas, dispensando as considerações políticas e, consequentemente, também as estratégicas. Nesse tipo de guerra, a política ainda daria início à guerra, mas, começadas as hostilidades, o objetivo político original seria deslocado pela lógica propriamente combatente até o desfecho do enfrentamento (Diniz, 2002). 
11. Parece-nos óbvio que a falha em reconhecer o conceito pleno de defesa é o que tem mantido os proponentes da abordagem do Balanço Ataque-Defesa no caminho errado por tanto tempo (Diniz, 2002).

12. Trindade paradoxal, na tradução de Paret e Howard (Clausewitz, 1984) e trindade esquisita no entendimento de Diniz (2002).

13. A publicação e divulgação dessa obra seguiu vários percalços, o que resultou no seu limitado reconhecimento. Primeiro, ela teve seu processo de publicação encerrado meses antes do início da Primeira Guerra Mundial, por isso apenas em 1915 houve sua primeira tiragem, de 400 livros. Segundo, o próprio Corbett seria tomado pela guerra, como um dos principais assessores de Churchill e não teria condições de compartilhar ou debater seus resultados. Terceiro, esse livro seguiu como contrato com o Comitê da Defesa do Império e com o benefício de um grupo de oficiais da seção histórica e os relatórios e documentos restritos do Japão sobre a guerra, consequentemente a sua limitada tiragem era consequência de sua confidencialidade estabelecida pela divisão de inteligência da Marinha Real. Por isso, era uma publicação restrita a oficiais da Marinha Real do Reino Unido. Quarto, em 1994, ela receberia uma segunda edição pela Naval War Institute dos Estados Unidos, mas ainda com uma tiragem bastante limitada. Apenas em 2015 a obra seria disponibilizada amplamente, inclusive em formato digital.

14. Na medida em que pesquisas baseadas em Mahan não possuem proposições conceituais que abarquem a guerra em outros ambientes que o mar, a consequência lógica desse exercício é que um suposto Programa Mahaniano seria degenerativo em relação ao Programa Clausewitziano. 15. Só para citar alguns: Hooker (2005); Kurth (2005); Peters (1998); Bunker (1997); Lynn (1996). 


\section{A CIÊNCIA DA GUERRA: EPISTEMOLOGIA \\ E PROGRESSO NOS ESTUDOS ESTRATÉGICOS}

\section{RESUMO}

Propõe-se a aderência do campo dos Estudos Estratégicos à Metodologia dos Programas de Pesquisa Científica de Imre Lakatos como forma de prover rigor e cientificidade ao estudo do fenômeno bélico. Apresenta-se como o Programa Clausewitziano atende aos requisitos da rigorosa epistemologia lakatosiana, delimitando o seu núcleo duro, o seu cinturão protetor de hipóteses auxiliares e suas orientações heurísticas. Conclui-se com uma breve ilustração da força heurística e da progressividade do Programa Clausewitziano, a partir das contribuições de Julian S. Corbett, e com um exemplo de mudança teórica interprogramática, a partir da proposta de Michael Handel.

Palavras chave: Lakatos; Clausewitz; Estudos Estratégicos; Progresso científico.

\section{ABSTRACT}

We propose the adherence of Strategic Studies to Imre Lakatos's Methodology of Scientific Research Program as a way to provide scientific rigor to the study of war. We argue how the Clausewitzian Program fulfills Lakatos's rigorous epistemological requirements, while delimiting its hard core, protective belt and heuristic orientations. We conclude with a succinct illustration of the program's progressiveness and heuristic strength, as a result of the works of Julian S. Corbett, and with an example of an interprogrammatic theoryshift, based on Michael Handel's contribution.

Key-words: Lakatos; Clausewitz; Strategic Studies; Scientific progress.

Recebido em: 20/01/2016. Aprovado para publicação em: 11/05/2016. 